\title{
Responses in Skin Microcirculation to Vestibular Stimulation Before and During Motion Sickness
}

\author{
Ognyan I. Kolev, Claes Möller, Gert Nilsson and Lita Tibbling
}

\begin{abstract}
Background: Observation of physiological changes during motion sickness is required to quantify the degree of sickness. The review of the literature does not show unifying results. An objective symptom of motion sickness is facial pallor. It reflects changes in skin microcirculation which have not been measured so far. Methods: Eleven healthy volunteers susceptible to motion sickness were subjected to eccentric vertical axis rotation. The dynamics and the correspondence of the changes in skin blood flow in two segments, forehead and finger, were measured by laser Doppler flowmeter. Results and Conclusions: The difference in the microcirculatory skin blood flow across the phases of motion sickness is significant for the forehead but not for the fingertip; the established dynamics of the forehead blood flow during motion sickness will be of benefit in quantifying the degree of sickness; there is no correlation between the blood flow changes in both measured areas; the rhythmic blood flow fluctuation increases during motion sickness; there is a difference between the blood flow responses to vestibular stimulation before the appearance of motion sickness and in the course of the sickness. Laser Doppler flowmetry is a reliable method in quantifying the degree of motion sickness.
\end{abstract}

RÉSUMÉ: Réponse de la microcirculation cutanée à la stimulation vestibulaire avant et pendant le mal des transports. Introduction: On doit observer des changements physiologiques pendant le mal des transports (MT) pour pouvoir quantifier le degré de malaise. Une revue de la littérature ne montre pas de résultats uniformes. Un symptôme objectif du mal des transports, qui n'a pas été mesuré à date, est la pâleur faciale qui reflète des changements dans la microcirculation. Méthodes: Onze volontaires normaux sensibles au mal des transports ont été soumis à la rotation eccentrique autour d'un axe vertical. Nous avons mesuré la dynamique et la correspondance des changements du flot sanguin cutané dans deux segments, le front et les doigts, au moyen d'un vélocimètre Doppler au laser. Résultats et Conclusions: La différence dans le débit sanguin de la microcirculation cutanée pendant toutes les phases du mal des transports est significative au niveau du front mais pas au bout des doigts. La dynamique du débit snaguin au front pendant le mal des transports sera utile pour quantifier le degré de malaise. II n'existe pas de corrélation entre les changements du débit sanguin dans les deux régions où nous l'avons mesuré. La fluctuation rythmique du débit augmente pendant le mal des transports. Il existe une différence entre les résponses du débit sanguin à la stimulation vestibulaire avant l'apparition du mal des transports et pendant le malaise. La vélocimétrie Doppler au laser est une méthode fiable pour quantifier le degré de mal des transports.

Can. J. Neurol. Sci. 1997; 24: 53-57

Observation of physiological changes during motion sickness (MS) is required to quantify the degree of sickness. The review of the literature does not show unifying results. Some experiments have shown physiological changes which correspond to MS. ${ }^{1,2}$ In other experiments no systematic change has been found, for instance in blood pressure, heart rate, respiratory rate, and EEG ${ }^{3}$ and conflicting results have been reported..$^{1,2}$

An objective symptom of MS is facial pallor. It reflects changes in skin microcirculation which have not been measured so far. It is important to study the dynamics of the microcirculatory blood flow. One could expect changes which will give information on the dynamics of the sickness and could be helpful in quantifying the degree of sickness. The pallor has been reported to affect only the facial area. Therefore it is of interest to investigate whether the change of blood flow (BF) is only in this region or if it is a generalized skin reaction and, if so, whether this change is similar in different skin regions or not (in this case the results will indicate some redistribution of the skin

From the Departments of Otorhinolaryngology (C.M., L.T.) and Biomedical Engineering (G.N.), University Hospital, Linköping, Sweden, O.I.K. is a visiting Research Scientist, at present in Universities Space Research Association, Division of Space Life Sciences, Houston, Texas, USA.

RECEIVED APRIL 19, 1996. ACCEPTED IN FINAL FORM SEPTEMBER 29, 1996

Reprint requests to: Ognyan I. Kolev, M.D., Universities Space Research Association, Division of Space Life Sciences, 3600 Bay Area Boulevard, Houston, Texas, USA 77058 
$\mathrm{BF})$. Besides the face another region appropriate for $\mathrm{BF}$ measure could be the fingertip, because it has dense sympathetic innervation (and is therefore sensitive to different changes) and it is quite distant from the face segment. It has to be mentioned also that the blood flow varies with location because of different densities of the skin vasculature. ${ }^{4}$

It is likely that neuronal and hormono-humoral mechanisms influence the cutaneous BF during MS, because both take part in its regulation and it is known that both change their activity during MS. ${ }^{1,5}$

The studies, so far, on the vegetative responses to sicknessprovoking motion do not show what is happening with microcirculatory blood flow prior to $\mathrm{MS}$, in the initial period of vestibular irritation - when motion stimuli act but motion sickness symptoms have not yet appeared.

The present study was done to examine the dynamics and the correspondence of the changes in skin microcirculatory blood flow in two skin segments, forehead and finger, during vestibular stimulation: (i) in the period before motion sickness appears and (ii) during the course of the sickness.

\section{Material and Methods}

Eleven healthy volunteers aging 23-40 years, susceptible to motion sickness, were subjected to vestibular stimulation. This consists of vertical axis rotations (alternating - clockwise and counterclockwise, at every 25 turns) on a turning system, which continue throughout the whole study period. The subjects were sitting in a chair, situated 1 meter away from the center of rotation in order to influence the otholitic system. The speed of rotation was $150 \mathrm{degrees} / \mathrm{sec}$. The probes (optical fibre with measuring head) of a laser Doppler flowmeter (Perimed Inc., Stockholm, Sweden) were positioned on the forehead and on the distal phalange of the palmar surface of the index finger. The rotation started after 20 minutes rest in the rotating chair and at least 6 minutes basal activity at the rest state was recorded and averaged.
The room temperature was in the range 20-22 degrees Celsius.

The blood flow varies with location and between the subjects too. ${ }^{4}$ Besides the flow values obtained by the laser Doppler flowmeter are expressed as voltage measurements (Figure 1), and these measurements are usually compared to a baseline value in order to express results as percentage change from that baseline. ${ }^{6,7}$ Therefore in this study we selected to measure the blood flow changes in percent from the baseline as a more informative way to present the results. Changes, in percent, of the mean blood flow (averaged, between many maximal and minimal values of the flow variation, over the $30 \mathrm{sec}$. period immediately before the report of each increasing level of gastric symptoms) were calculated for each level of sickness: 1. epigastric awareness (EA); 2. epigastric discomfort (ED); 3. Nausea I (NI) - a moderately intensive and persistent unpleasant sensation; 4 . Nausea II (NII) - strong sensation; and 5. retching (R) (Pensacola Scale ${ }^{8}$ ), separately for forehead and finger skin regions.

Both microcirculatory BF and vessel diameter of the caliber of arterioles are temporally and spatially variable, and this variability manifests itself in the rhythmic luminal changes which cause corresponding flow variation. These two phenomena received the terms of vasomotion and flow fluctuation (variation) respectively. The vasomotion is regulated by local pacemaker mechanisms and is controlled by summation of local and central signals. ${ }^{9}$ The fluctuation of the BF (measured as ratio between the difference of the mean of all maximal $(A)$ and the mean of all minimal (B) BF values of the rhythmic BF variation, and the sum of these values), calculated in percent was averaged for each level of sickness. (The used formula is:

$\frac{(A-B) / 2}{(A+B) / 2} \times 100=\mathrm{BF}$ variability $\left.(\%)\right)$

The changes in the BF in the initial period of vestibular stimulation (before symptoms of MS to appear) defined as vestibular stress (VS) were also calculated.

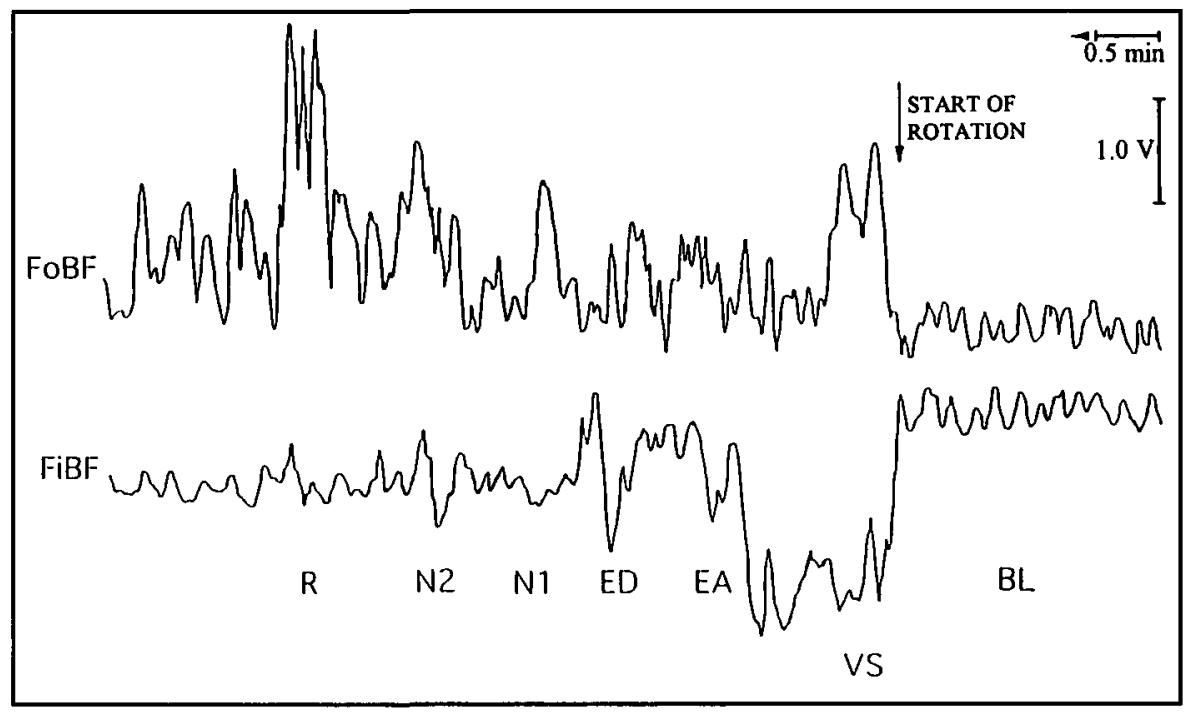

Figure 1: Parallel record of the time course of skin blood flow in the forehead and the fingertip before and during the vestibular stimulation. (Abbreviations: FoBF - forehead blood flow, FiBF - fingertip blood flow, BL - basal level, VS - vestibular stress, EA - epigastric awareness, ED - epigastric discomfort, $N 1$ - nausea l, N2 - nausea 2, $R$ - retching). 
In addition the facial color change during MS was estimated by visual observation of two test operators. Three different assessments were used: pallor, flushing, or no change.

For statistical analysis we applied one way ANOVA (to assess the change of the BF across the phases of MS, with the progress of the sickness), Students t-test and correlation analysis using "Statgraphics" statistical package (V5.0; Statistical Graphic Corp., USA). A $p$ value less than 0.05 was regarded as statistically significant.

\section{Results}

Nine subjects reached frank sickness (retching), two - Severe Malaise (Nausea II) (Pensacola Scale ${ }^{8}$ ). Two subjects reported that after the end of the vestibular stimulation the still persisting symptoms of nausea and warmth did not decrease linearly but rather fluctuated in a wavelike manner. Generally the $\mathrm{BF}$ of the forehead increased during VS and MS (Figures 1, 2A) $(p<0.01)$. (In one subject a persistent opposite effect was recorded). However facial pallor was observed in all subjects. Generally the BF of the finger showed opposite changes (Figures 1, 2B) it decreased during VS and MS $(p<0.05$ ). (Here also an inverse reaction was registered in one subject).

The change of the mean BF in the forehead across the phases of MS was significant $(A N O V A, p<0.01)$. However that was not established for the mean BF in the finger (ANOVA, $p>0.1$ ). Blood flow fluctuation increased compared to baseline $(p<0.01)$ in both measured sites during MS (Figure 3). This increase was not significantly different across the phases of MS $(p>0.2)$ (Figure 3). The vestibular stress caused significant change only in the finger $\mathrm{BF}$ fluctuation (Figure $3 \mathrm{~B}$ ).

The average correlation between the blood perfusion in both measured regions - forehead and finger, across time was 0.456 . The average correlation between the variability of the BF across time in the forehead and finger measured areas was 0.305.

\section{Discussion}

This study was conducted in order to investigate the dynamics of microcirculation in the progress of MS, and the difference between blood flow prior MS and in the course of MS. The results indicate that the difference in the skin $\mathrm{BF}$ across the phases of MS is significant for the forehead but not for the fingertip; there is no correlation between the BF changes in both measured areas; the rhythmic BF fluctuation increases during MS; there is a difference between the autonomic responses to VS and to MS.

The established dynamics of the forehead BF during MS will be of benefit in quantifying the degree of sickness.

The "paradoxical" effect - increased BF in the forehead during facial pallor has the following explanation. The color of the skin is defined mainly by the capillaries. During pallor the lumen of the capillaries decreases. However the microcirculatory blood flow is defined not only by the capillaries but also by arterioles, venules and arterio-venous anastomoses. Presumably the increased BF passes mostly through the shunts. This is in agreement with the subjects' feeling of warmth (it is known that the arterio-venous anastomoses have an important role in thermoregulation). Another possible mechanism is a compensatory increase in velocity of $\mathrm{BF}$ through narrowed arterioles.

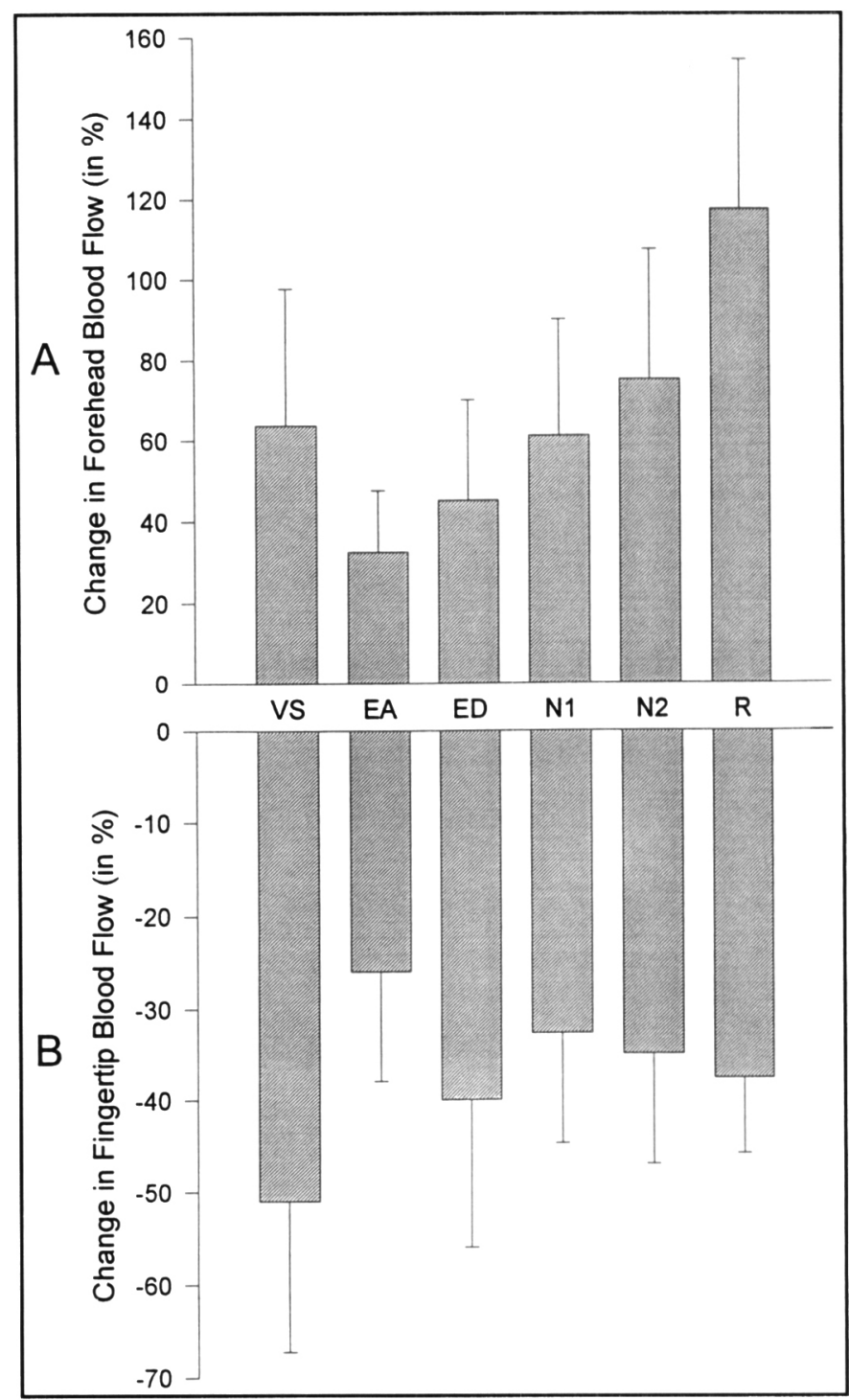

Figure 2: Change (mean $\pm S E$ bars) of the forehead skin blood flow $(A)$ and the fingertip skin blood flow (B) during vestibular stress and motion sickness. (For the abbreviations see Figure 1).

The difference in the pattern of the reaction between forehead and finger BF, corresponds to described findings in other studies - weak correlation between vegetative reactions in different regions to some stimulations. As examples we could cite orienting reflex - increased $\mathrm{BF}$ in the forehead while in the limbs it decreases; ${ }^{10}$ cold challenge - vasoconstriction in the extremities but no change in the forehead skin;" diving reflex - peripheral vasoconstriction, unequal in different regions, ${ }^{12}$ etc. The studies, so far, give evidence that the skin $\mathrm{BF}$ is regulated by a set of several different mechanisms. These mechanisms are: sympathetic noradrenergic vasoconstriction, sympathetic non-adrenergic atropine-resistant vasodilatation, vasodilatation induced by release of a vasoactive substance from sweat glands activated by cholinergic sympathetic sudomotor neurons, ${ }^{13.14}$ vasodilatation by non-adrenergic (neuropeptide) mechanism linked to the parasympathetic nerves. ${ }^{15}$ Wallin ${ }^{16}$ argues that it is not clear whether the vasodilatation is due to inhibition of vasoconstrictor 


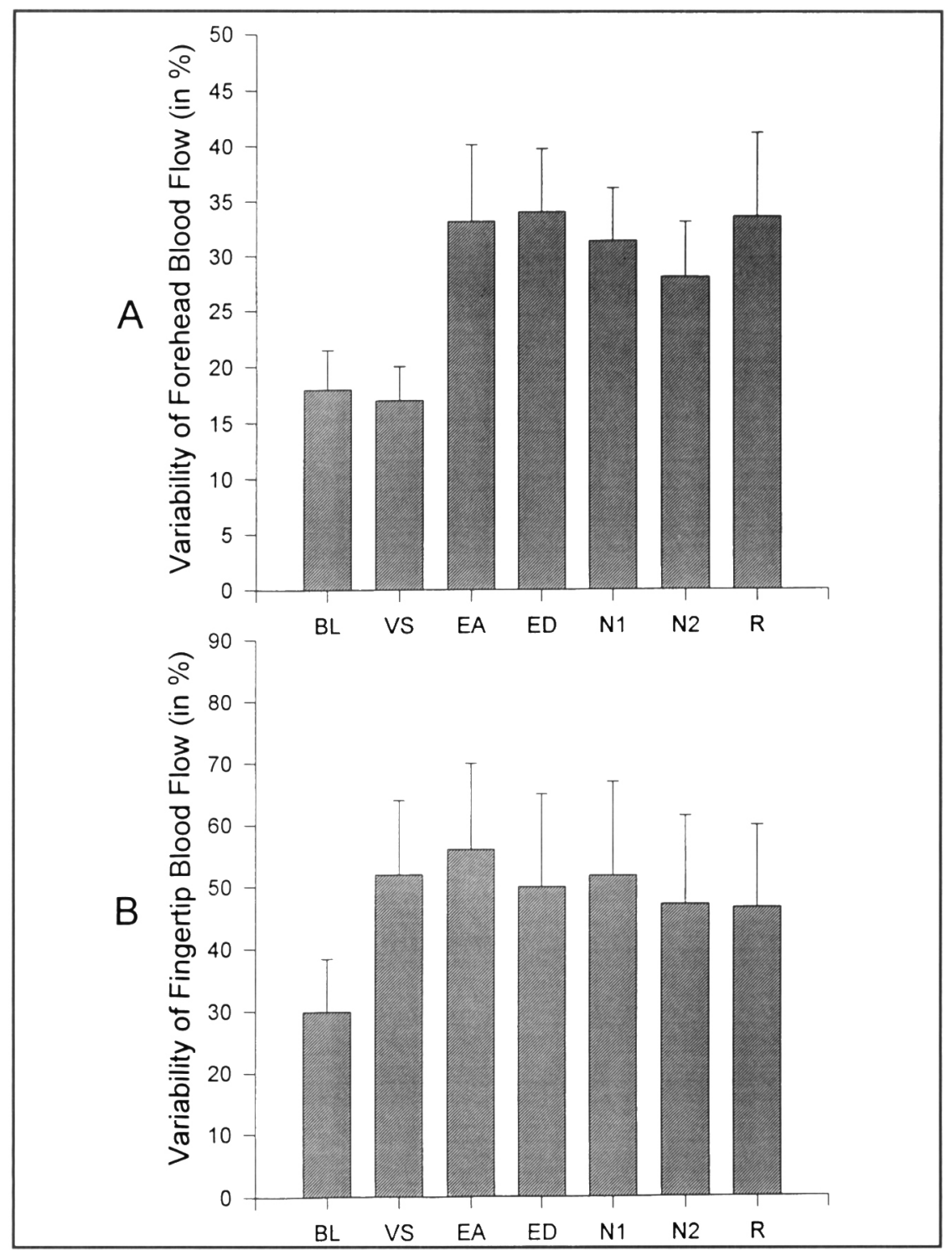

Figure 3: Blood flow fluctuation (mean variability \pm SE bars) in the forehead $(\boldsymbol{A})$ and finger tip (B) skin microvasculature during rest - basal level, vestibular stress, and motion sickness. (For the abbreviations see Figure 1).

nerve traffic or to active (impulse induced) vasodilatation. Our discussion is that the difference between forehead and fingertip $\mathrm{BF}$ reactions could be explained by the fact that the different mechanisms for BF regulation are not equally present in different skin regions and are not equally activated.

The different patterns of the autonomic response to vestibular stress and motion sickness, found in this study, show differences in the mechanisms of their genesis. The autonomic responses to the vestibular stimulation, in the initial period, generally resemble those of an unspecific stressful reaction to different sensory cues (e.g., acoustic ${ }^{7}$ and visual (our unpublished data)), somewhere between orienting and startle reflexes. ${ }^{10}$

Spontaneous fluctuation of the microcirculatory BF (rhythmic vasomotion in the microvasculature) has been recognized for years, however the mechanisms underlying vascular pacemaker activity are only hypothesized. ${ }^{4,17-19}$ Our study allows us to suggest that this pacemaker is under vestibular (through central nervous system) influence. That is, motion stimuli cause changes in the amplitude of microvascular activity - spontaneous $\mathrm{BF}$ fluctuation.

In conclusion, the results of the present study indicate that the difference in the skin blood perfusion across the phases of motion sickness is significant for the forehead but not for the fingertip; the established dynamics of the forehead blood flow during motion sickness will be of benefit in quantifying the degree of sickness; there is no correlation between the blood flow changes in both measured areas; the rhythmic blood flow fluctuation increases during motion sickness; there is a difference between the flux responses before motion sickness appear and during the course of the sickness; laser Doppler flowmetry is a reliable method for quantifying the degree of motion sickness. 


\section{ACKNOWLEDGEMENTS}

The authors thank the personnel of the Vestibular laboratory of the Linköping University Hospital for their help in conducting this study. This work was supported by the Swedish Institute (Stockholm).

\section{REFERENCES}

1. Harm DL. Physiology of motion sickness symptoms. In: Crampton $\mathrm{GH}$, ed. Motion and Space Sickness. Boca Raton, Fl.: CRC Press, 1990; 153-179.

2. Money KE. Motion sickness. Physiol Rev 1970; 50: 1-39.

3. Graybiel A, Lackner JR. Evaluation of the relationship between motion sickness symptomatology and blood pressure, heart rate, and body temperature. Aviat Space Environ Med 1983; 51: 211214.

4. Johnson JM. The cutaneous circulation. In: Shepherd AP, Oberg PA, eds. Laser-Doppler Blood Flowmetry. Boston: Kluwer Academic Publishers, 1990; 121-139.

5. Drummer C, Stromeyer H, Riepl RL, et al. Hormonal changes after parabolic flight: implications on the development of motion sickness. Aviat Space Environ Med 1990; 61: 831-838.

6. Aratow M, Hargens AR, Meyer JU, Arnold SA. Postural responses of head and foot cutaneous microvascular flow and their sensitivity to bed rest. Aviat Space Environ Med 1991; 62: 246-251.

7. Kolev OI, Nilsson G, Tibbling L. Influence of intense sound stimuli on skin microcirculation. Clin Autonomic Res 1995; 5: 187-190.

8. Graybiel A, Wood CD, Miller EF, Cramer DB. Diagnostic criteria for grading the severity of acute motion sickness. Aerosp Med $1968 ; 453-455$.
9. Intaglietta M. Vasomotion as normal microvascular activity and a reaction to impared homeostasis. In: Intaglietta $\mathrm{M}$, ed. Vasomotion and Flow Modulation in the Microcirculation. Basel: Karger AG, 1989; 1-10.

10. Sokolov EN. Higher nervous functions: the orienting reflex. Ann Rev Physiol 1963; 25: 545-580.

11. Bruck K. Thermic balance and body temperature regulation. In: Schmidt RF, Thews G, eds. Human Physiology, vol 4. New York: Springer, 1983; 18-46.

12. Heath ME, Downey JA. The cold face test in clinical autonomic assessment. Clin Sci 1990; 78: 139-147.

13. Janig W. Functions of the sympathetic innervation of the skin. In: Loewy AD, Spyer KM, eds. Central Regulation of Autonomic Functions. New York: Oxford University Press, 1990; 334-349.

14. Bell C, Janig W, Kummel H, Xu H. Differentiation of vasodilator and sudomotor responses in the cat paw pad to preganglionic sympathetic stimulation. J Physiology 1983; 364: 93-104.

15. Lundblad L. Neuropeptides and autonomic nervous control of the respiratory mucosa. In: Mygind N, Pipkorn U, Dahl R, eds. Rhinitis and Asthma. Copenhagen: Munksgaard, 1990; 65-75.

16. Wallin BG. Neural control of human skin blood flow. J Autonomic Nerv Syst 1990; 30 (Suppl.): 185-190.

17. Tenland T, Salerud EG, Nilsson GE, Oberg PA. Spatial and temporal variations in human skin blood flow. Int J Microcirc Clin Exp $1983 ; 2: 81-90$.

18. Colantuoni A, Bertuglia S, Intaglietta M. Quantitation of rhythmic diameter changes in arterial microcirculation. Am J Physiol 1984; 246: H508-H517.

19. Colantuoni A, Bertuglia S, Intaglietta $M$. Variations of rhythmic diameter changes at the arterial microvascular bifurcations. Pflugers Arch 1985; 403: 289-295. 